\title{
Phytochemical Investigation and Characterization on the Stem Bark Extract of Croton macrostachyus
}

\author{
Teshale Ayano Begeno \\ Department of Chemistry, College of Natural and Computational Science, Wolkite University, Ethiopia. \\ P.O.Box: 07 Wolkite University, Wolkite, Ethiopia
}

\begin{abstract}
Croton macrostachyus which is called 'rush foil' or 'broadleaved croton is a multipurpose, medium sized, droughtdeciduous pioneer tree. It is a tall tree found in tropical regions of Africa. The genus Croton belongs to the family Euphorbiaceae, which commonly known as the 'spurge' family, and it is known as 'Bisana' (in Amharic). Traditionally, C. macrostachyus used for treatment of malaria, rabies, gonorrhea, wound, diarrhea, hepatitis, jaundice, scabies, toothache, abdominal pain, cancer, typhoid, pneumonia and gastrointestinal disorders and as ethno-veterinary medicine. The air dried and powdered plant material $(400 \mathrm{~g})$ was first soaked with $500 \mathrm{~mL} \mathrm{n}$ hexane for 48 hours and yielded $2 \mathrm{~g}$ of $\mathrm{n}$-hexane extract. Marc was soaked with $500 \mathrm{~mL}$ of chloroform for 36hours and afforded $3.5 \mathrm{~g}$ of chloroform extract. Finally, Marc was soaked with $500 \mathrm{~mL}$ of methanol and yielded $18 \mathrm{~g}$ of methanol extract. The chloroform extract of the stem bark of $C$. macrostachyus afforded a compound coded as EO. Its Structural determination was accomplished by means of spectroscopic techniques, namely IR, ${ }^{1} \mathrm{H}$ NMR, ${ }^{13} \mathrm{C}$ NMR and DEPT-135. The compound, EO was isolated and characterized from the stem bark of $C$. macrostachyus. Generally, more advanced chromatographic techniques are required to isolate more compounds from stem bark of C. macrostachyus. Also MS and 2D NMR spectroscopic techniques are needed to fully characterize the isolated compound.
\end{abstract}

Keywords: C. macrostachyus; ethno-veterinary; characterization; chromatographic techniques; spectroscopic techniques.

DOI: $10.7176 / \mathrm{CPER} / 63-01$

Publication date:October $31^{\text {st }} 2020$

\section{Introduction}

Plants are invaluable and fundamental to almost all life on earth. They provide wide range of uses to human beings such as medicine, food, shelter, clothing, fuel wood for cooking, timber for construction, utensils, as well as fodder for cattle. They also recycle essential nutrients of ecosystems, establishing soils and maintaining soil fertility in addition to protecting areas of water catchments. Moreover, they keep ecological and climatic balance, facilitate, and control rainfall through the process of evaporative transpiration. ${ }^{1,2}$ Croton macrostachyus Hochst. ex Delile is a species of the genus Croton L., Euphorbiaceae family, commonly known as the spurge family. Croton macrostachyus is a medium sized, drought-deciduous pioneer tree which regenerates naturally in less productive sites including forest edges, mountain slopes, and waste grounds under a wide range of ecological conditions.$^{3-5}$ Croton macrostachyus is regarded as a multipurpose tree by subsistence farmers in Ethiopia, Kenya, and Tanzania ${ }^{5-8}$, as it is ofen grown and managed in home gardens for provision of several ecosystem goods and services. In Ethiopia, for example, C. macrostachyus is a major tree intercropped in agroecosystems in order to increase soil productivity in midaltitude and semiarid areas. ${ }^{9}$

\subsection{Croton macrostachyus}

The genus Croton belongs to the family Euphorbiaceae (which commonly known as the 'spurge' family). ${ }^{10}$ It is known as Bisana' (in Amharic). ${ }^{11}$ And consists of approximately 1300 species of trees, shrubs and herbs distributed in tropical and subtropical regions of the world. ${ }^{12}$ Croton macrostachyus which is called 'rush foil' or 'broadleaved croton is a multipurpose, medium sized, drought-deciduous pioneer tree. It is a tall tree found in tropical regions of Africa. ${ }^{13}$ Elsewhere in Africa, C. macrostachyus has been reported to occur in Angola, Burundi, Cameroon, Central Africa, Ghana, Guinea, Ivory Coast, Kenya, Malawi, Mozambique, Nigeria, Rwanda, Sudan, Tanzania, Uganda, Zaire, and Zambia. ${ }^{14}$ It is native to Eritrea, Ethiopia, Kenya, Nigeria, Tanzania and Uganda. ${ }^{15}{ }^{16}$ In Ethiopia, C. macrostachyus occurs in regions between 1300 and $2500 \mathrm{~m}$ with annual rainfall ranging between 750 and $2000 \mathrm{~mm}$. Croton macrostachyus is commonly found on forest edges along rivers, around lakes, woodlands, wooded grasslands and along roadsides. ${ }^{10}$ The tree is quite persistent, regenerating large numbers of coppices or shoots, even when it is repeatedly lopped or degraded. Provided that environmental and soil conditions are favorable, C. macrostachyus does establish well and can grow quite fast on reasonably good and well-drained soils, but prefers red or loam soils to vertisoils. The latter soils are known for their shrink-swell properties (during the dry and wet seasons, respectively), and for getting waterlogged during the rainy season. ${ }^{10}$ Croton macrostachyus (Euphorbiaceae) is a large tree with cylindrical trunk. The stem is more or less pyramidal in shape with widespread branches. The stem is gray clear, smooth and fissure with age. Leaves are almost as heart-shaped large that long, 
they have 10 to $15 \mathrm{~cm}$ of length; they are flexible, green or brunette according to the season and present some prominent ribs. Flowers are regrouped in inflorescence on stems of about $25 \mathrm{~cm}$ of long. They are visible but their life span is very short. They are colour creamy and slightly fragrant yellow. Fruits are regrouped along an axis.$^{17}$ The name of Croton comes from a Greek word 'Kroton' which means ticks, because of the seeds' resemblance to ticks, the specific name "macrostachyus" is a contraction of two words, the Greek word "macro" meaning large and "stachyus" relating to the spike, hence, a species characterized by large spikes. ${ }^{18}$ C. macrostachyus is regarded as a multipurpose tree by subsistence farmers in Ethiopia, Kenya, and Tanzania and the species has potential in playing an important role in the primary healthcare. The bark, fruits, leaves, roots, and seeds of C. macrostachyus are reported to possess diverse medicinal properties and $C$. macrostachyus is used as herbal medicine for at least 61 human and 20 animal diseases and ailments. In the distribution area there is a high degree of medicinal use consensus for bleeding, blood clotting, cancer, constipation, diarrhea, epilepsy, malaria, pneumonia, purgative, ringworm, skin diseases or infections, stomach ache, typhoid, worm expulsion, and wounds. ${ }^{19,20}$

\subsection{Phytochemical constituent of $C$. macrostachyus}

The genus Croton is rich in terpenoids (diterpenoids and triterpenoids), alkaloids, flavonoids, lignoids, proanthcyanidins and volatile oils containing monoterpenoids, sesquiterpenoids and some shikimate-derived compounds. Previous studies showed the existence of crotin (a chalcone), lupeol (a triperpene), crotepoxide (a cyclohexane diepoxide), proteins, fatty acids, saponins, resins and alkaloids. ${ }^{19,21}$ The activity of C. macrostachyus stem bark extracts is comparable to studies where antiplasmodial activity has been related to a range of several classes of secondary plant metabolites including alkaloids and sesquiterpenes, triterpenes, flavonoids, inonoids, and quassinoids. ${ }^{21}$

\subsection{Medicinal value of $C$. macrostachyus}

Traditionally C. macrostachyus used for treatment of malaria, rabies, gonorrhea, wound, diarrhea, hepatitis, jaundice, scabies, toothache, abdominal pain, cancer, typhoid, pneumonia and gastrointestinal disorders and as ethnoveterinary medicine. ${ }^{22-24}$ Pharmacological studies on $C$. macrostachyus indicate that it has a wide range of pharmacological activities such as anthelmintic, antibacterial, antimycobacterial, antidiarrheal, antifungal, anticonvulsant and sedative, antidiabetic, anti-inflammatory, antileishmanial, antioxidant, antiplasmodial, and larvicidal effects. ${ }^{19}$ The leaves and shoots of $C$. macrostachyus are used to treat fever and oedema and also mashed leaves used for treatment of hemorrhoids. Moreover, the maceration of $C$. macrostachyus stem bark is used as abortifacient and uterotonic to expel retained placenta. ${ }^{25}$

\section{Materials and Methods}

\subsection{Plant Material}

The C. macrostachyus stem bark was collected from morsito Shero kebele Haqoro, Misha Woreda, Hadiya Administrative Zone, Southern Nations Nationalities and People Regional State (SNNPR). It was authenticated by a botanist and specimen was stored at the National Herbarium of Addis Ababa University (Voucher no.TA004), Addis Ababa, Ethiopia.

\subsection{Instruments, Apparatus and Chemicals}

${ }^{1} \mathrm{H}$ and ${ }^{13} \mathrm{C}$ NMR spectra were recorded on a Bruker Advance $400 \mathrm{MHz}$ spectrometer (Germany) in $\mathrm{CDCl}_{3}$ with TMS as internal standard. The ultra-violet and visible (UV-Vis) spectra were taken on GENESY'S 2PC UV-Vis scanning spectrometer (USA) (200-800nm). IR spectra were obtained on Perkin-Elmer BX infrared spectrometer (USA) (400-4000 $\left.\mathrm{cm}^{-1}\right)$ using KBr. Melting point was recorded using digital melting point apparatus; RV-10basic Rotavapor (Germany) was used for separation of solvents. Analytical thin layer chromatograms were run on $0.2 \mathrm{~mm}$ thick layer of silica gel coated on aluminium foil. Column chromatography was performed using silica gel (70-230mesh). In this study, all the chemicals were provided by Hi-Media Co. including methanol, acetone, chloroform, n-hexane, and others.

Some of the apparatus were used: funnels, round bottom flasks, vials, glass wares, refrigerator, Whatman No.1 filter papers, grinder, drying oven, measuring cylinders, TLC Chamber, and others.

\subsection{Extraction and Isolation}

The air dried and powdered plant material $(400 \mathrm{~g})$ was first soaked with $500 \mathrm{ml} \mathrm{n}$-hexane for 48 hours with frequently shaking and the extract was collected by filtering and concentrated under reduced pressure using the RV-10 basic Rotavapor. The solvent free residue was then soaked with 500ml of chloroform (CF) for 36 hours with frequently shaking and the extract was collected. This filtrate was evaporated under reduced pressure using the Rotavapor. 

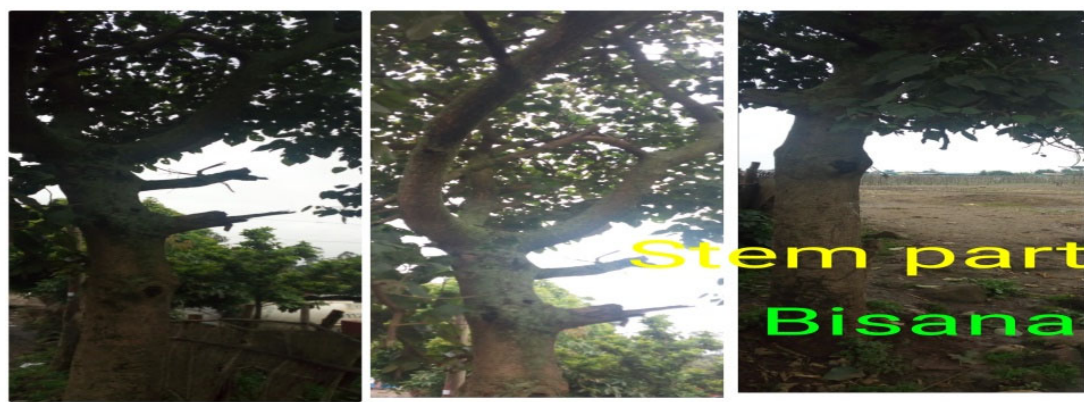

Fig. 1. C. macrostachyus: (Picture taken by Teshale A. during data collection)

Finally, the solvent free residue was soaked with $500 \mathrm{ml}$ of methanol, and then it was filtrated by using Whatman no.1 filter paper and concentrated under reduced pressure using the Rotavapor and its extract was afforded many spots on TLC. There was no visible spot for n-hexane extract, but chloroform extracts showed colored spots by using solvent system of n-hexane: chloroform (2:8) and crude extract was dissolved in itself with equivalent amount of silica gel, dried using Rotavapor and applied to a silica gel $(200 \mathrm{~g})$ column chromatography which was packed with n-hexane (100\%).

The scheme of extraction is shown below:
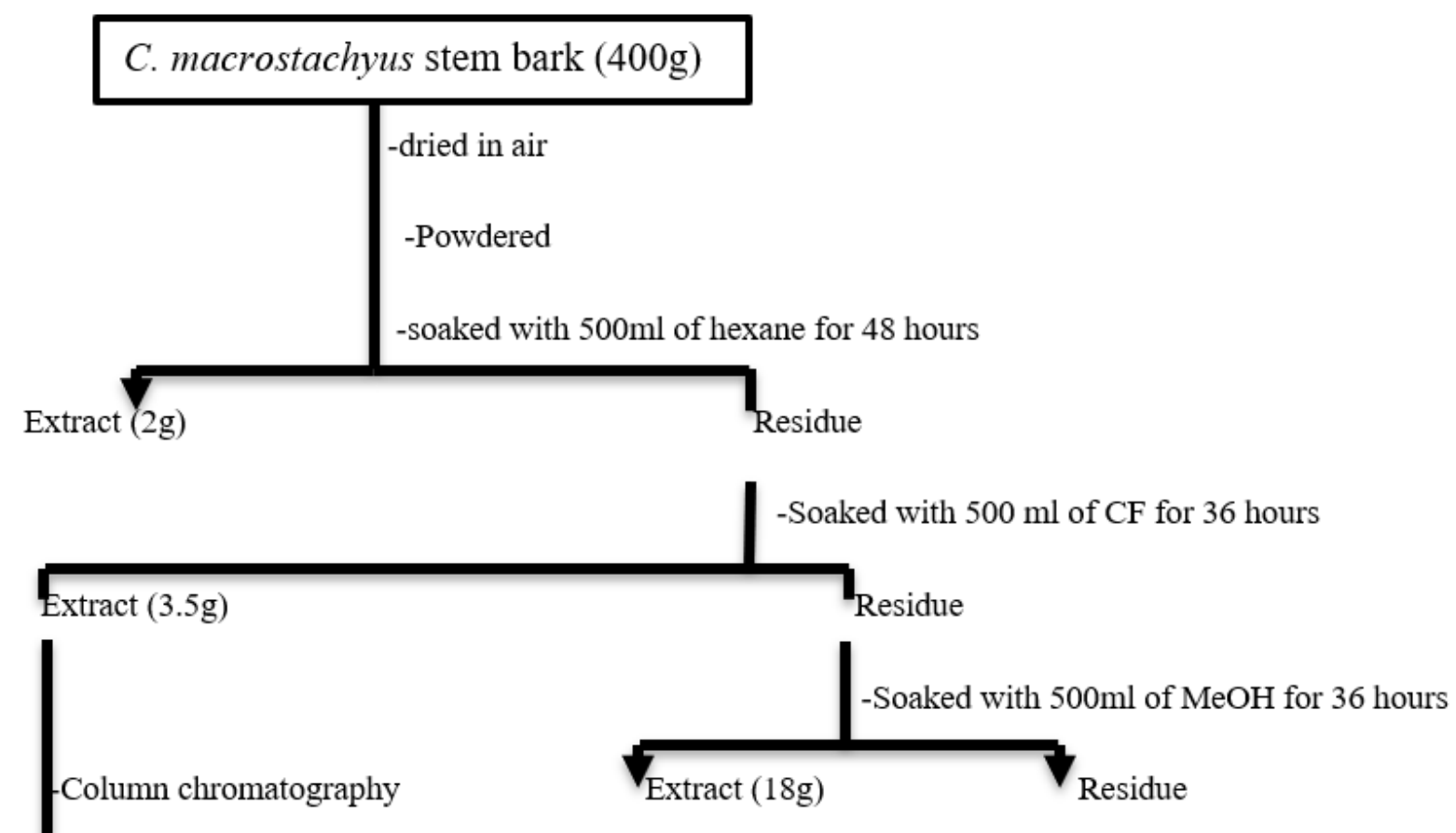

(200g Silica gel) in n-hexane $(100 \%)$

Totallv. 260 fractions were collected

Fraction86: 56mg Compound, EO

Scheme 1. Method used to extract and isolate of stem bark of $C$. macrostachyus 
Table 1. Column chromatography of C. macrostachyus stem bark extract of chloroform by using solvent systems: n-hexane, chloroform and Methanol

\begin{tabular}{llll}
\hline S. no. & Solvent systems & Solvent ratio & Collected fractions \\
\hline $\mathbf{1}$ & n-hexane & $100 \%$ & $1-4$ \\
$\mathbf{2}$ & n-hexane: chloroform & $9: 1$ & $5-9$ \\
$\mathbf{3}$ & n-hexane: chloroform & $8: 2$ & $10-16$ \\
$\mathbf{4}$ & n-hexane: chloroform & $7: 3$ & $17-22$ \\
$\mathbf{5}$ & n-hexane: chloroform & $6: 4$ & $23-31$ \\
$\mathbf{6}$ & n-hexane: chloroform & $5: 5$ & $32-45$ \\
$\mathbf{7}$ & n-hexane: chloroform & $4: 6$ & $46-58$ \\
$\mathbf{8}$ & n-hexane: chloroform & $3: 7$ & $59-75$ \\
$\mathbf{9}$ & n-hexane: chloroform & $2: 8$ & $76-96$ \\
$\mathbf{1 0}$ & n-hexane: chloroform & $1: 9$ & $97-121$ \\
$\mathbf{1 1}$ & Chloroform & $100 \%$ & $122-143$ \\
$\mathbf{1 2}$ & chloroform: methanol & $9: 1$ & $144-156$ \\
$\mathbf{1 3}$ & chloroform: methanol & $8: 2$ & $157-165$ \\
$\mathbf{1 4}$ & chloroform: methanol & $7: 3$ & $166-176$ \\
$\mathbf{1 5}$ & chloroform: methanol & $6: 4$ & $177-186$ \\
$\mathbf{1 6}$ & chloroform: methanol & $5: 5$ & $187-197$ \\
$\mathbf{1 7}$ & chloroform: methanol & $3: 7$ & $198-220$ \\
\hline $\mathbf{1 8}$ & chloroform: methanol & $1: 9$ & $221-238$ \\
\hline $\mathbf{1 9}$ & methanol & $100 \%$ & $239-260$ \\
\hline
\end{tabular}

Totally 260 fractions were collected. Out of 260 fractions which were collected using the solvent systems increased polarity, only those fractions from 76-96 showed the characteristic colored spots on TLC. The remaining fractions did not show the characteristic colored spots on TLC. Among fractions 76-96, fraction 86 showed single spot on TLC using the solvent system n-hexane: chloroform (2:8. Finally, the dried sample of this fraction was afforded $56 \mathrm{mg}$ of the compound, EO.

\section{Results and Discussion}

The air dried and powdered C. macrostachyus stem bark $(400 \mathrm{~g})$ were extracted with solvents of $\mathrm{n}$-hexane, chloroform, and methanol and their yields $2 \mathrm{~g}, 3.5 \mathrm{~g}$, and $18 \mathrm{~g}$, respectively. These extracts when developed on TLC both the n-hexane and chloroform extracts have shown colored spots, but methanol extract was afforded many spots on TLC. The yellow organic extract of chloroform (3.5g) was subjected to column chromatography on silica gel and 260 fractions were collected.

Table 2. Results of phytochemical screening $C$. macrostachyus stem bark

\begin{tabular}{lll}
\hline Phytochemical constituents & Bark extracts & \\
\cline { 2 - 3 } Tannins & Chloroform & Methanol \\
Saponins & + & + \\
Flavonoids & + & + \\
Terpenoids & + & + \\
Glycosides & + & + \\
Alkaloids & + & + \\
Steroids & + & + \\
Phenols & + & + \\
\hline
\end{tabular}

[NB :(+) indicate the presence of Phytochemical Constituents]

\subsection{Characterization of Compound, EO}

The compound, EO was obtained as a white solid that showed a characteristic color change to orangic on TLC plate. It has retention factor, $\mathrm{RF}$ value 0.68 using hexane: chloroform $(2: 8)$ as solvent system. In the IR spectrum of the compound, EO the absorption band at $3300 \mathrm{~cm}^{-1}$ showed the $\mathrm{O}-\mathrm{H}$ stretching that indicated the presence of a hydroxyl group. The strong absorption band at $2900 \mathrm{~cm}^{-1}$ showed the presence of the C-H stretching of the olefinic group. The weak absorption band at $2886 \mathrm{~cm}^{-1}$ showed the presence of the $\mathrm{C}-\mathrm{H}$ stretching for $\mathrm{sp}^{3}$ groups. The strong absorption band at $1610 \mathrm{~cm}^{-1}, 1595 \mathrm{~cm}^{-1}$, and $1630 \mathrm{~cm}^{-1}$ showed the presenc e of the olefinic $\mathrm{C}=\mathrm{C}$ stretching. The strong absorption band at $1720 \mathrm{~cm}^{-1}$ showed the presence of the ketone carbonyl group $(-\mathrm{C}=\mathrm{O})$ stretching. The absorption band at $1256 \mathrm{~cm}^{-1}$ showed the presence of the $\mathrm{C}-\mathrm{O}$ bond stretching. 
Table3: IR spectral peak values and functional groups obtained from the stem bark extract of $C$. macrostachyus (EO)

\begin{tabular}{lll}
\hline Extract prepared in & peak values in $\mathbf{~ c m}^{-\mathbf{1}}$ & functional groups \\
\hline & 3300 & $-\mathrm{OH}$ (hydroxyl group) \\
Chloroform & 2900 & $\mathrm{Sp}^{2} \mathrm{C}-\mathrm{H}$ stretching \\
& 2886 & $\mathrm{SP}^{3} \mathrm{C}-\mathrm{H}$ stretching \\
& 1630,1610 and 1695 & Olefinic group of $\mathrm{C}=\mathrm{C}$ stretching \\
& 1720 & Carbonyl group of $-\mathrm{C}=\mathrm{O}$ stretching \\
& 1472 & Methylene group bending \\
& 1363 & Methyl group bending \\
& 1256 & CO bond stretching \\
\hline
\end{tabular}

The ${ }^{1} \mathrm{H}$ NMR spectrum showed, the coupled proton peaks, which is triplet peaks at $\delta 1.40 ; 1.17$, integrating for two protons corresponded to the methylene proton which was attached to C-1. Coupled proton peaks, which is quartet peaks at $\delta 1.60 ; 1.43$, integrating for two protons, which were corresponded to the methylene proton groups and assigned to $\mathrm{C}-2$. The pentet peaks at 83.31 , integrating for one proton, corresponded to the methine proton group that assigned at C-3. Coupled proton peaks, which is doublet peaks at $\delta 2.32 ; 1.95$, which integrating for two protons corresponded to the methylene proton groups and attached to $\mathrm{C}-4$. Triplet peaks at $\delta 5.34$, integrating for one proton corresponded to the methine proton, which was assigned to C-6. Coupled proton peaks, which is triplet peaks at $\delta 2.15 ; 1.90$, integrating for two protons corresponded to the methylene protons which were attached to $\mathrm{C}-7$. The pentet peaks at $\delta 1.93$, integrating for one proton, corresponded to the methine proton and assigned to C8 . The doublet peaks at $\delta 2.42$, integrating for one proton, corresponded to the methine proton and assigned to $\mathrm{C}$ 9. The coupled proton peaks, which is doublet peaks at $\delta 2.41 ; 2.12$, integrating for two protons corresponded to the methylene protons which were attached to C-12. The pentet peaks at $\delta 2.20$ which integrating for one proton corresponded to the methine proton and attached to $\mathrm{C}-13$. The quartet peaks at $\delta 2.30$ which integrating for one proton corresponded to the methine proton and, which was attached to C-14. The triplet peaks at $\delta 5.54$ which integrating for one proton corresponded to the methine proton and attached to C-15. The triplet peaks at $\delta 5.54$ which integrating for one proton corresponded to the methine proton and attached to C-16. The quartet peaks at $\delta 2.83$ which integrating for one proton corresponded to the methine proton and, which was attached to C-17. The triplet peaks at $\delta 5.37$ which integrating for one proton corresponded to the methine proton and attached to C-18. The quartet peaks at $\delta 5.30$ which integrating for one proton corresponded to the methine proton and, which was attached to $\mathrm{C}-19$. The quartet peaks at $\delta 1.80$ which integrating for two protons corresponded to the methylene protons and, which were attached to $\mathrm{C}-20$. The quartet peaks at $\delta 1.26$ which integrating for two protons corresponded to the methylene protons and, which were attached to C-21. The multiple peaks at $\delta 1.87$ which integrating for one proton corresponded to the methine proton and, which was attached to C-22. Doublet peaks at $\delta 1.11$, which integrating for six protons corresponded to the methyl protons and that were attached to C-23 and C24 . Singlet peak at $\delta 1.29$, which integrating for three protons corresponded to the methyl protons and attached to C-25.

The ${ }^{13} \mathrm{C}$ NMR and DEPT-135 spectrum of compound, EO showed well resolved resonance of $25 \mathrm{C}$ atoms of which $3,7,12$, and 3 of them were namely, methyl, methylene, methine, and quaternary carbon groups, respectively. 
Table 4: ${ }^{1} \mathrm{H}$ NMR spectral data of compound (EO)

\begin{tabular}{llllll}
\hline S. No. & Peaks $(\boldsymbol{\delta})$ & $\begin{array}{l}\text { Peak } \\
\text { multiplicities }\end{array}$ & Proton No. & Assigned carbon & Remark \\
\hline $\mathbf{1}$ & $1.40 ; 1.17$ & Triplet & Two & C-1 & Methylene \\
$\mathbf{2}$ & $1.60 ; 1.43$ & Quartet & Two & C-2 & methylene \\
$\mathbf{3}$ & 3.31 & Pentet & One & C-3 & Methine \\
$\mathbf{4}$ & $2.32 ; 1.95$ & Doublet & Two & C-4 & Methylene \\
$\mathbf{5}$ & 5.34 & Triplet & One & C-6 & methine \\
$\mathbf{6}$ & $2.15 ; 1.90$ & Triplet & Two & C-7 & Methylene \\
$\mathbf{7}$ & 1.93 & Pentet & One & C-8 & Methine \\
$\mathbf{8}$ & 2.42 & Doublet & One & C-9 & Methine \\
$\mathbf{9}$ & $2.41 ; 2.12$ & Doublet & two & C-12 & methylene \\
$\mathbf{1 0}$ & 2.20 & Pentet & One & C-13 & Methine \\
$\mathbf{1 1}$ & 2.30 & Quartet & One & C-15 and C-16 & Methine \\
$\mathbf{1 2}$ & 5.54 & Triplet & Two & C-17 & Methine \\
\hline $\mathbf{1 3}$ & 2.83 & Quartet & One & C-18 & Methine \\
$\mathbf{1 4}$ & 5.37 & Triplet & One & C-19 & Methine \\
$\mathbf{1 5}$ & 5.30 & Quartet & One & C-20 & Methylene \\
\hline $\mathbf{1 6}$ & 1.80 & Quartet & Two & C-21 & Methylene \\
\hline $\mathbf{1 7}$ & 1.26 & Quartet & Two & C-22 & Methine \\
\hline $\mathbf{1 9}$ & 1.87 & Multiple & One & C-23 and C-24 & Methyl \\
\hline $\mathbf{2 0}$ & 1.11 & Doublet & Six & C-25 & Methyl \\
\hline
\end{tabular}

The ${ }^{13}$ CNMR and DEPT-135 spectrum of compound (EO) showed well resolved resonance of 25 carbon atoms and from them were: three methyl groups, seven methylene groups, twelve methine groups and three quaternary carbons.

Table 5: ${ }^{13} \mathrm{C}$ NMR and DEPT-135 (400 $\left.\mathrm{MHz}, \mathrm{CDCl}_{3}\right)$ spectral data of Compound (EO)

\begin{tabular}{|c|c|c|c|}
\hline Carbon No. & ${ }^{13} \mathrm{C}$ NMR (in ppm) & DEPT (in ppm) & Remark \\
\hline 1 & 30.60 & 30.62 & $\mathrm{CH}_{2}$ \\
\hline 2 & 32.71 & 32.70 & $\mathrm{CH}_{2}$ \\
\hline 3 & 70.00 & 70.00 & $\mathrm{CH}$ \\
\hline 4 & 39.00 & 39.10 & $\mathrm{CH}_{2}$ \\
\hline 5 & 141.55 & - & C(Quaternary carbon) \\
\hline 6 & 132.96 & 132.94 & $\mathrm{CH}$ \\
\hline 7 & 28.87 & 28.85 & $\mathrm{CH}_{2}$ \\
\hline 8 & 31.91 & 31.90 & $\mathrm{CH}$ \\
\hline 9 & 61.20 & 61.21 & $\mathrm{CH}$ \\
\hline 10 & 39.05 & - & C (Quaternary carbon) \\
\hline 11 & 210.00 & - & C (Quaternary carbon) \\
\hline 12 & 48.21 & 48.22 & $\mathrm{CH}_{2}$ \\
\hline 13 & 43.00 & 43.10 & $\mathrm{CH}$ \\
\hline 14 & 45.90 & 45.86 & $\mathrm{CH}$ \\
\hline 15 & 133.90 & 133.83 & $\mathrm{CH}$ \\
\hline 16 & 133.72 & 133.71 & $\mathrm{CH}$ \\
\hline 17 & 50.40 & 50.40 & $\mathrm{CH}$ \\
\hline 18 & 13097 & 130.96 & $\mathrm{CH}$ \\
\hline 19 & 130.87 & 130.86 & $\mathrm{CH}$ \\
\hline 20 & 27.60 & 27.61 & $\mathrm{CH}_{2}$ \\
\hline 21 & 40.23 & 40.22 & $\mathrm{CH}_{2}$ \\
\hline 22 & 29.45 & 29.44 & $\mathrm{CH}$ \\
\hline 23 & 24.67 & 24.67 & $\mathrm{CH}_{3}$ \\
\hline 24 & 24.67 & 24.67 & $\mathrm{CH}_{3}$ \\
\hline 25 & 23.56 & 23.55 & $\mathrm{CH}_{3}$ \\
\hline
\end{tabular}

Finally, from the all above data, namely IR spectral data, ${ }^{13} \mathrm{C}$ NMR, DEPT, and ${ }^{1} \mathrm{H}$ NMR spectral data the suggested structure of compound, EO would be shown below: 


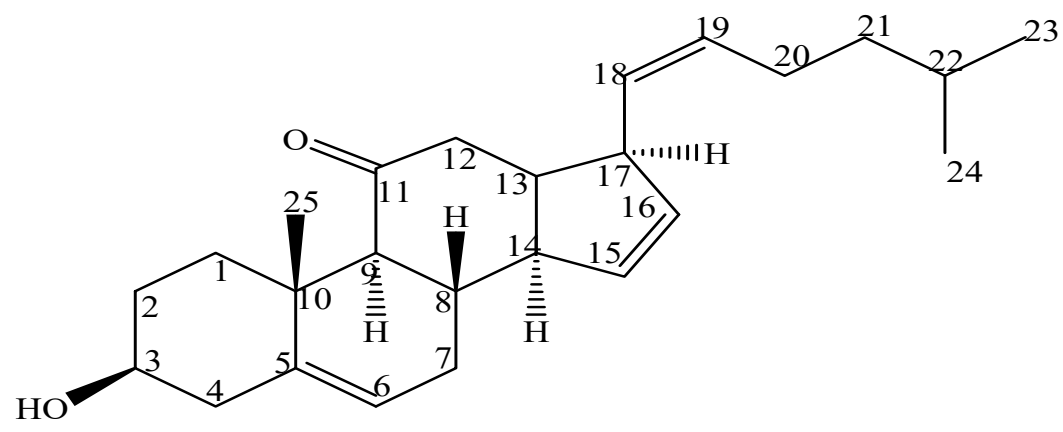

Fig. 2. The proposed structure of the compound, EO

\section{Conclusions and Recommendations}

C. macrostachyus used for treatment of malaria, rabies, gonorrhea, wound, diarrhea, hepatitis, jaundice, scabies, and as ethno-veterinary medicine. The C. macrostachyus stem bark extracts is comparable to studies where antiplasmodial activity has been related to a range of several classes of secondary plant metabolites including alkaloids and sesquiterpenes, triterpenes, flavonoids, inonoids, and quassinoids. In the this study, C. macrostachyus stem bark were showed the presence of phytochemical constituents such as alkaloids, flavonoids, terpenoids, saponins, tannins, steroids, glycosides, and phenols of chloroform and methanol extracts. The C. macrostachyus stem bark was extracted with solvents of $\mathrm{n}$-hexane, chloroform, and methanol and their yields $2 \mathrm{~g}, 3.5 \mathrm{~g}$, and $18 \mathrm{~g}$, respectively. The organic extract of chloroform $(3.5 \mathrm{~g})$ was subjected to column chromatography on silica gel and 260 of fractions were collected. From the IR spectrum of the compound, EO the absorption band at $3300 \mathrm{~cm}^{-1}$ showed the O-H stretching that indicated the presence of a hydroxyl group. The strong absorption band at $2900 \mathrm{~cm}^{-}$ ${ }^{1}$ showed the presence of the $\mathrm{C}-\mathrm{H}$ stretching of the olefinic group. The strong absorption band at $1610 \mathrm{~cm}^{-1}, 1595 \mathrm{~cm}^{-}$ ${ }^{1}$, and $1630 \mathrm{~cm}^{-1}$ showed the presenc e of the olefinic $\mathrm{C}=\mathrm{C}$ stretching. The strong absorption band at $1720 \mathrm{~cm}^{-1}$ showed the presence of the ketone carbonyl group $(-\mathrm{C}=\mathrm{O})$ stretching. Lastly, from this study, the compound EO was elucidated and characterised by incorporating by spectroscopic techniques such as IR spectral data, ${ }^{13} \mathrm{C}$ NMR, DEPT, and ${ }^{1} \mathrm{H}$ NMR spectral data acquired.

Despite the traditional use of this plant for the treatments of various ailments, in many parts of the world there is limit report on phytochemical analysis on the C. macrostachyus stem bark extracts, context of our country. Thus, this study may oblige as point of departure for researchers who are inspired and interested to conduct such type of research in the future.

\section{Acknowledgements}

The author would like to thank almighty one God, and families for their support of finance sources and praying for the success of this study.

\section{Competing Interests}

Authors have declared that no competing interests exist.

\section{Reference}

1. John Willey and Sons Ltd. Chichester, (1996): Cotton CM. Ethnobotany: Principles and Applications, 242.

2. Martin GJ, (1995): Ethnobotany: A Method Manual, Chapman and Hall, London.

3. A. R. Smith, (1987): "Euphorbaceae," in Flora of Tropical East Africa, R. M. Polhill, Ed., A A Balkema, Rotterdam, The Netherlands, pp. 20-391.

4. M. G. Gilbert, (1995): "Flora of Ethiopia and Eritrea," in Euphorbiaceae, S. Edwards, T. Mesfn, and I. Hedberg, Eds., Addis Ababa University, Addis Ababa, Ethiopia, pp. 265-380.

5. K. Wakjira and L. Negash, (2013): "Germination responses of Crotonmacrostachyus (Euphorbiaceae) to various physico-chemical pretreatment conditions," South African Journal of Botany, vol. 87, pp. 76-83.

6. A.B. Tesemma, A. Birnie, and B. Tengnas, (1993): "Useful trees and shrubs for ethiopia: identifcation, propagation and management for agricultural and pastoral communities," Technical Handbook no. 5, Regional Soil Conservation Unit/SIDA, Regional Soil Conservation Unit/SIDA, Nairobi, Kenya.

7. D. A. Hines and K. Eckman, (1993): Indigenous Multipurpose Trees for Tanzania: Uses and Economic Benefts to the People, Food and Agriculture Organization of the United Nations, Rome, Italy.

8. P. Maundu and B. Tengnas, (2005): Useful Trees and Shrubs for Kenya, World Agroforestry Centre, East and Central Africa Regional Programme (ICRAF-ECA), Technical Handbook 35, Nairobi, Kenya.

9. J. Dechasa, "Influence of Croton macrostachyus on maize yield: Traditional inter-crop farming system," Walia, vol. 1998 , no. 20, p. pp, 1999. 
10. Negash L. (2010): A Selection of Ethiopia's Indigenous Trees: Biology, Uses and Propagation Techniques. Addis Ababa University Press, Addis Ababa, Ethiopia pp 386.

11. Karunamoorthi K. and Ilango K. (2010): Larvicidal activity of Cymbopogon citratus (DC) and Croton macrostachyus against Anopheles arabiensis Patton, a potent malaria vector. Eur Rev Med Pharmacol Sci; 14:57-62.

12. Salatino A., Salatino M.L.F. and Giuseppina N.J., (2007): Braz. Chem. Soc. pp18, 11.

13. Bum E.N., Ngah E., Mune R.M.N., Ze Minkoulou D.M., Talla E., Moto F.C.O., Ngoupaye G.T., Taiwe G.S., Rakotonirina A. and Rakotonirina S.V. (2012): Epilepsy Behav. 24: 319.

14. Friis I. (1992): Forests and forest trees of northeast tropical Africa. Their natural habitats and distribution patterns in Ethiopia, Djibouti and Somalia. Kew Bulletin, Additional Series, XV. Her Majesty's Stationery Office, London pp.396.

15. Kapingu C.M., Guillaume D., Mbwambo H.Z., Moshi J.M., Uliso .C.F. and Mahunnah A.L.R (2000): Diterpenoids from the roots of Croton macrostachys. Phytochem., 54:767-770.

16. Orwa C., Mutua A., Kindt R., Jamnadass R. and Simons A. (2009): Agroforestry Database: a tree reference and selection guide version. pdf accessed on 2 April 2015.

17. Stuart KL., and Graham L., (1973): Alkaloids Biosynthesis in croton Flavens. Phytochemistry. 12:1067-1072.

18. Tolossa K, Debela E, Athanasiadou S, Tolera A, Ganga G, Houdijk J. Ethno-medicinal study of plants used for treatment of human and livestock ailments by traditional healers in South Omo, Southern Ethiopia. $J$ Ethnobiol Ethnomed. 2013; 9(1): 32.

19. Carlet J., Jarlier V., Harbarth S., Voss A., Goossens H., Pittet D., (2012): Ready for a world without antibiotics? The pensieres antibiotic resistance calls to action. Antimicrob Resist Infect Control; 1: 11.

20. Khameneh B, Diab R, Ghazvini K, Bazzaz B., (2016): Breakthroughs in bacterial resistance mechanisms and the potential ways to combat them. Microb Pathog.; 95: 32-42.

21. Kiranmayi ChB, Krishnaiah N, Mallika EN. Escherichia coli O157:H7-An emerging pathogen in foods of animal origin. Vet World. 2010; 3(8): 382-389.

22. Krishnaiah D., Sarbatly R., Bono A., (2007): Phytochemical antioxidants for health and medicine: A move towards nature. Biotechnology Molecular Biology; 1: 97-104.

23. Lai PK., Roy J., (2004): Antimicrobial and chemo preventive properties of herbs and species. Curr Med Chem.; 11: $1451-1460$.

24. Lee JH., (2003): Methicillin (oxacillin)-resistant Staphylococcus aureus strains isolated from major food animals and their potential transmission to humans. App Environ Microbiol.; 69(11): 6489-6494.

25. LeJeune JT., Besser TE., Hancock DD., (2001): Cattle water troughs as reservoirs of Escherichia coli O157. Appl Environ Microbiol; 67. 